\title{
Acceptance of COVID-19 Vaccine in Pakistan: A Nationwide Cross-Sectional Study
}

Mohammad Aadil Qamar ${ }^{1}$, Omar Irfan ${ }^{2}$, Rubaid A. Dhillon ${ }^{3}$, Areesh Bhatti ${ }^{4}$, Mir Ibrahim Sajid ${ }^{5}$, Safia Awan ${ }^{5}$, Wajiha Rizwan ${ }^{6}$, Ali Bin Sarwar Zubairi ${ }^{7}$, Zouina Sarfraz ${ }^{8}$, Javaid Ahmed Khan ${ }^{7}$

1. Internal Medicine, Ziauddin University, Karachi, PAK 2. Pediatrics, Centre for Global Child Health, Hospital for Sick Children, Toronto, CAN 3. Internal Medicine, Riphah International University, Rawalpindi, PAK 4. Pediatrics, The Aga Khan University, Karachi, PAK 5. Internal Medicine, The Aga Khan University, Karachi, PAK 6. Pediatrics, The Children Hospital and Institute of Child Health, Lahore, PAK 7. Pulmonology, The Aga Khan University, Karachi, PAK 8. Internal Medicine, Fatima Jinnah Medical University, Lahore, PAK

Corresponding author: Zouina Sarfraz, zouinasarfraz@gmail.com

\section{Abstract \\ Introduction}

The coronavirus disease 2019 (COVID-19) vaccine is available across various countries worldwide, with public-private partnerships ensuring all individuals are vaccinated through a phased approach. Irrespective of the geographical spread, several myths pertaining to the COVID-19 vaccine have stemmed, ultimately limiting the national administration of vaccines and rollouts. This study assessed the acceptance of the COVID-19 vaccine among the general public in Pakistan.

\section{Methods}

A pre-validated questionnaire was administered from January 2021 to February 2021 to assess the public attitude and acceptance of the COVID-19 vaccine. Logistic regression analyses were run to identify factors associated with the acceptance among the population.

\section{Results}

A total of 936 responses were elicited, where $15 \%$ perceived their risk of being infected at $20-30 \%$ with an overall $70 \%$ agreeing to be vaccinated if recommended. Multivariate analysis identified higher acceptance in the male gender, healthcare workers, and students. Of all, 66\% respondents chose healthcare workers and public officials, whereas $15.6 \%$ chose scientific literature, and $12.9 \%$ chose social media as the most reliable source of COVID-19 information.

\section{Conclusion}

Given the relatively greater trust in healthcare providers for information regarding COVID-19, healthcare workers ought to be on the frontline for vaccine campaigns and public outreach efforts, with governmental efforts in addition to the promotion of scientific materials for population-level understanding.

Review began 07/07/2021 Review ended 07/10/2021 Published 07/24/2021

\section{(c) Copyright 2021}

Qamar et al. This is an open access article distributed under the terms of the Creative Commons Attribution License CC-BY 4.0., which permits unrestricted use, distribution, and reproduction in any medium, provided the original author and source are credited.
Categories: Infectious Disease, Public Health

Keywords: covid-19, vaccination, acceptability, pakistan, public health

\section{Introduction}

The coronavirus disease 2019 (COVID-19) pandemic began as a cluster of respiratory tract infections of unknown origin in Wuhan, China. As a mutated variant of the coronavirus family and given extensive contact with the center of the outbreak, COVID-19 dispersed worldwide. As of June 29, 2021, 181.5 million confirmed cases have been reported worldwide to the World Health Organization (WHO), with 3.9 million casualties [1,2]. A total of 0.95 million confirmed COVID-19 cases have been reported from Pakistan, as of June 29, 2021 [1,2]. Notably, the vaccine doses administered as of June 29, 2021, are 2.9 billion, as reported to the WHO [1].

Pakistan comprises a diverse population comprising a multitude of ethnic, religious, and socio-economic groups. Among them lies a fraction of the population which has previously opposed the use of polio vaccinations, resulting in Pakistan being one of the three countries that still reports polio cases [3]. Among the many challenges that were faced in the acceptance of polio vaccination programs, one was the alleged myth concerning the biological effects of the vaccine [4]. The myth was propagated primarily by certain religious clerics, which was also raised in the case of COVID-19 vaccines, ranging from the vaccine's ability to alter DNA to the insertion of microchips in controlling human behaviors [4]. As a low- and middle-income country (LMIC) with poor health infrastructure and a limited budget to provide advanced point-of-care treatment, Pakistan would have had to enforce the mantra of "prevention is better than cure," to counter the 
myths [5].

With five vaccines (AstraZeneca, Sinopharm, CanSino, Sputnik V, and Gamaleya) approved for use in Pakistan as of June 29, 2021, along with the phased rollout approach of mass vaccination, this study aimed to assess the acceptance of the COVID-19 vaccine among the general public. This study also aimed to inform medical communities about the causes of gaps in vaccine administration in LMIC, with relevant public health findings to ensure uniform vaccine rollouts.

\section{Materials And Methods}

A large-scale, cross-sectional study was conducted to assess the acceptability of the COVID-19 vaccine among the Pakistani population from January 2021 to February 2021. Ethical approval was obtained from the Ethical Review Committee of Islamic International Medical College, Rawalpindi (Riphah/IIMC/ ERC/146). An online questionnaire prepared on Google Forms both in Urdu and English was disseminated to be filled by consenting individuals aged 18 years or more. The study investigators in consultation with subject experts administered a previously validated questionnaire for the study [6,7]. The questionnaire was run through pilot testing consisting of 40 participants comprising various field experts and layman individuals to ensure the clarity and relevance of the contents being assessed. The responses obtained during the pilot testing were not included during the final analysis of data.

The survey consisted of two main sections; first, respondent demographics (socio-economic status and relevant comorbidities), and second, vaccine attitude, to assess vaccine acceptance under different circumstances. The first section incorporated demographic questions with select options addressing age, gender, province, education, employment, income, marital status, occupation, and comorbidity. The second section employed the use of polar questions and the Likert scale on four occasions to assess the level of trust the people placed on the government, reliability of media as a source of accurate pandemic information, compliance to get vaccinated, and to ascertain the severe effects of COVID-19 if the disease was contracted.

The sample size was calculated using OpenEpi (Version 3.01; Open Source Epidemiologic Statistics for Public Health), which was estimated to be 683 participants (95\% confidence interval $\{\mathrm{CI}\}$, bound on the error of $3 \%$, and 50\% acceptability). The final enrollment included 1000 participants to account for the accretion rate, and to compensate for any missing data in the final dataset. To analyze the data, SPSS Version 25 (Chicago, IL: IBM ${ }^{\circledR}$ SPSS ${ }^{\circledR}$ Statistics) was utilized. Quantitative variables were represented as mean and standard deviation (SD), whereas frequencies were used for qualitative variables. The comparison of acceptance of vaccines among different groups within the socio-demographic was assessed using the chi-square test and/or Fisher's exact test, where appropriate. Univariate and multivariate analyses were performed to compare the acceptance of the vaccine with the variables of interest. The test result was considered statistically significant if the p-value was 0.05 or less.

\section{Results}

Of the 1000 forms that were distributed, a total of 936 participants completed the online questionnaire, yielding a response rate of $93.6 \%$. A significant majority of the population were females $(n=558,59.6 \%)$, aged between 20 years and 29 years $(n=411,43.9 \%)$, not-married $(n=708,75.6 \%)$ and were residents of the province, Punjab $(n=485,51.8 \%)$. A detailed analysis of the patient demographics can be visualized in Table 1.

\begin{tabular}{|c|c|c|c|c|}
\hline Variable & Total: $\mathbf{n}(\%)$ & Vaccine accepted N=656: n (\%) & Vaccine refused $\mathrm{N}=280: \mathrm{n}(\%)$ & p-value \\
\hline \multicolumn{4}{|c|}{ Age (years) } & \multirow{7}{*}{$<0.001$} \\
\hline 18-19 & $359(38.4)$ & 226 (34.5) & $133(47.5)$ & \\
\hline $20-29$ & 411 (43.9) & $319(48.6)$ & $92(32.9)$ & \\
\hline 30-39 & 98 (10.5) & 69 (10.5) & $29(10.4)$ & \\
\hline $40-49$ & $25(2.7)$ & 19 (2.9) & $6(2.1)$ & \\
\hline $50-59$ & $28(3)$ & $16(2.4)$ & $12(4.3)$ & \\
\hline$>60$ & $15(1.6)$ & $7(1.1)$ & $8(2.9)$ & \\
\hline \multicolumn{5}{|l|}{ Gender } \\
\hline Male & 378 (40.4) & $283(43.1)$ & 95 (33.9) & \multirow[t]{2}{*}{0.009} \\
\hline Female & $558(59.6)$ & $373(56.9)$ & $185(66.1)$ & \\
\hline \multicolumn{4}{|l|}{ Province } & \\
\hline
\end{tabular}




\section{Cureus}

\begin{tabular}{|c|c|c|c|c|}
\hline Sindh & 341 (36.4) & $261(39.8)$ & $80(28.6)$ & \multirow{5}{*}{0.01} \\
\hline Punjab & $485(51.8)$ & $318(48.5)$ & $167(59.6)$ & \\
\hline Balochistan & $34(3.6)$ & $22(3.4)$ & $12(4.3)$ & \\
\hline Khyber Pakhtunkhwa & $64(6.8)$ & $47(7.2)$ & $17(6.1)$ & \\
\hline Gilgit-Baltistan & $12(1.3)$ & $8(1.2)$ & $4(1.4)$ & \\
\hline \multicolumn{4}{|l|}{ Education } & \multirow{7}{*}{0.003} \\
\hline No formal education & $21(2.2)$ & $10(1.5)$ & $11(3.9)$ & \\
\hline Primary school & $3(0.3)$ & $2(0.3)$ & $1(0.4)$ & \\
\hline Secondary school & 105 (11.2) & $80(12.2)$ & $25(8.9)$ & \\
\hline Bachelor/university & $608(65)$ & $441(67.2)$ & $167(59.6)$ & \\
\hline Master/PhD & $185(19.8)$ & $117(17.8)$ & $68(24.3)$ & \\
\hline Diploma & $14(1.5)$ & $6(0.9)$ & $8(2.9)$ & \\
\hline \multicolumn{4}{|l|}{ Occupation } & \multirow{8}{*}{$<0.001$} \\
\hline Unemployed & $149(15.9)$ & $105(16)$ & $44(15.7)$ & \\
\hline Retired & $6(0.6)$ & $6(0.9)$ & $0(0)$ & \\
\hline Private sector & $187(20)$ & $147(22.4)$ & $40(14.3)$ & \\
\hline Government employee & $44(4.7)$ & $38(5.8)$ & $6(2.1)$ & \\
\hline Business & $39(4.2)$ & $25(3.8)$ & $14(5)$ & \\
\hline Student & $505(54)$ & $334(50.9)$ & $171(61.1)$ & \\
\hline Unskilled worker & $6(0.6)$ & $1(0.2)$ & $5(1.8)$ & \\
\hline \multicolumn{4}{|l|}{ Income (in Pakistani rupees) } & \multirow{6}{*}{$<0.001$} \\
\hline$<10,000$ & $52(5.6)$ & $38(5.8)$ & $14(5)$ & \\
\hline 10,000-49,999 & $95(10.1)$ & $71(10.8)$ & $24(8.6)$ & \\
\hline $50,000-100,000$ & $94(10)$ & 75 (11.4) & $19(6.8)$ & \\
\hline$>100,000$ & $122(13)$ & $100(15.2)$ & $22(7.9)$ & \\
\hline Not applicable & $573(61.2)$ & $372(56.7)$ & $201(71.8)$ & \\
\hline \multicolumn{4}{|l|}{ Marital status } & \multirow{4}{*}{0.005} \\
\hline Married & $209(22.3)$ & $145(22.1)$ & $64(22.9)$ & \\
\hline Single & 708 (75.6) & $504(76.8)$ & $204(72.9)$ & \\
\hline Divorced & $19(2)$ & $7(1.1)$ & $12(4.3)$ & \\
\hline \multicolumn{4}{|l|}{ Occupation } & \multirow{4}{*}{0.003} \\
\hline Healthcare workers & $133(14.2)$ & $107(16.3)$ & $26(9.3)$ & \\
\hline Medical students & $298(31.8)$ & $216(32.9)$ & $82(29.3)$ & \\
\hline None of the above & $505(54)$ & $333(50.8)$ & $172(61.4)$ & \\
\hline Presence of COVID-19 infection in family or friends & $427(45.6)$ & $333(50.8)$ & $94(33.6)$ & $<0.001$ \\
\hline \multicolumn{4}{|l|}{ Comorbidity } & \multirow{3}{*}{0.69} \\
\hline Yes & $130(13.9)$ & $93(14.2)$ & 37 (13.2) & \\
\hline No & $806(86.1)$ & $563(85.8)$ & $243(86.8)$ & \\
\hline
\end{tabular}

TABLE 1: Characteristics of the study population $(\mathrm{N}=936)$ 
Around half of the study population ( $\mathrm{n}=427,45.6 \%$ ) reported a relative or a friend who had contracted COVID-19. The participants reported their perceptions toward COVID-19 and response towards the vaccine as a percentage (i.e. $0-10 \%, 10-20 \%$ ), shown in Table 2. One-third of the population believed that they had less than a $10 \%$ risk of contracting COVID- 19 , and only $20.2 \%$ of the population believed that they had more than $50 \%$ risk of contracting the virus (Table 2 ).

\begin{tabular}{|c|c|c|c|c|}
\hline Variable & $\begin{array}{l}\text { Total: } \mathrm{n} \\
\text { (\%) }\end{array}$ & $\begin{array}{l}\text { Vaccine accepted } N=656: \\
\text { n (\%) }\end{array}$ & $\begin{array}{l}\text { Vaccine refused } \mathrm{N}=\mathbf{2 8 0} \\
\mathrm{n}(\%)\end{array}$ & $\begin{array}{l}\mathrm{p}- \\
\text { value }\end{array}$ \\
\hline \multicolumn{4}{|l|}{ Perceived risk of being infected with COVID-19 } & \multirow{8}{*}{$<0.001$} \\
\hline $0-10 \%$ & $271(29)$ & $172(26.2)$ & $99(35.4)$ & \\
\hline $10-20 \%$ & $\begin{array}{l}111 \\
(11.9)\end{array}$ & 72 (11) & $39(13.9)$ & \\
\hline $20-30 \%$ & $\begin{array}{l}142 \\
(15.2)\end{array}$ & $95(14.5)$ & $47(16.8)$ & \\
\hline $30-40 \%$ & $\begin{array}{l}121 \\
(12.9)\end{array}$ & $82(12.5)$ & $39(13.9)$ & \\
\hline $40-50 \%$ & $\begin{array}{l}102 \\
(10.9)\end{array}$ & $84(12.8)$ & $18(6.4)$ & \\
\hline $50-60 \%$ & $91(9.7)$ & 71 (10.8) & $20(7.1)$ & \\
\hline$>60 \%$ & 98 (10.5) & $80(12.2)$ & $18(6.4)$ & \\
\hline $\begin{array}{l}\text { I will get vaccinated by a vaccine with } 95 \% \text { effectiveness (for a } \\
\text { cost) }\end{array}$ & $\begin{array}{l}722 \\
(77.1)\end{array}$ & 567 (86.4) & $155(55.4)$ & $<0.001$ \\
\hline $\begin{array}{l}\text { I will get vaccinated by a vaccine with } 50 \% \text { effectiveness (for a } \\
\text { cost) }\end{array}$ & $\begin{array}{l}386 \\
(41.2)\end{array}$ & $302(46)$ & $84(30)$ & $<0.001$ \\
\hline $\begin{array}{l}\text { If a vaccine with } 95 \% \text { effectiveness is made freely available, I will } \\
\text { get vaccinated }\end{array}$ & $\begin{array}{l}799 \\
(85.4)\end{array}$ & $615(93.8)$ & $184(65.7)$ & $<0.001$ \\
\hline $\begin{array}{l}\text { If a vaccine with } 50 \% \text { effectiveness is provided for free, I will get } \\
\text { vaccinated }\end{array}$ & $\begin{array}{l}521 \\
(55.7)\end{array}$ & $425(64.8)$ & $96(34.3)$ & $<0.001$ \\
\hline \multicolumn{4}{|l|}{ I have confidence in the reliability of media sources regarding COVID- 19} & \multirow{6}{*}{$<0.001$} \\
\hline Strongly disagree & $\begin{array}{l}104 \\
(11.1)\end{array}$ & $35(5.3)$ & $69(24.6)$ & \\
\hline Disagree & $\begin{array}{l}152 \\
(16.2)\end{array}$ & $96(14.6)$ & $56(20)$ & \\
\hline Neutral & $\begin{array}{l}316 \\
(33.8)\end{array}$ & 234 (35.7) & $82(29.3)$ & \\
\hline Agree & $\begin{array}{l}163 \\
(17.4)\end{array}$ & $127(19.4)$ & $36(12.9)$ & \\
\hline Strongly agree & $\begin{array}{l}201 \\
(21.5)\end{array}$ & $164(25)$ & 37 (13.2) & \\
\hline I get Influenza/flu vaccine/flu shots administered every year & $\begin{array}{l}233 \\
(24.9)\end{array}$ & $177(27)$ & $56(20)$ & 0.02 \\
\hline \multicolumn{4}{|l|}{ I have trust in the national government in controlling the pandemic } & \\
\hline Strongly disagree & $\begin{array}{l}106 \\
(11.3)\end{array}$ & $58(8.8)$ & $48(17.1)$ & \\
\hline Disagree & $\begin{array}{l}143 \\
(15.3)\end{array}$ & 88 (13.4) & 55 (19.6) & \multirow{2}{*}{$<0.001$} \\
\hline Neutral & $271(29)$ & $192(29.3)$ & $79(28.2)$ & \\
\hline
\end{tabular}




\section{Cureus}

\begin{tabular}{|c|c|c|c|c|}
\hline Agree & $\begin{array}{l}189 \\
(20.2)\end{array}$ & $148(22.6)$ & $41(14.6)$ & \\
\hline Strongly agree & $\begin{array}{l}227 \\
(24.3)\end{array}$ & $170(25.9)$ & $57(20.4)$ & \\
\hline \multicolumn{5}{|c|}{ If I contract COVID-19, it can be debilitating and dangerous to my health } \\
\hline Strongly disagree & $36(3.8)$ & $10(1.5)$ & $26(9.3)$ & \\
\hline Disagree & $65(6.9)$ & $42(6.4)$ & $23(8.2)$ & \\
\hline Neutral & 206 (22) & $119(18.1)$ & $87(31.1)$ & $<0.001$ \\
\hline Agree & $\begin{array}{l}263 \\
(28.1)\end{array}$ & $181(27.6)$ & $82(29.3)$ & \\
\hline Strongly agree & $\begin{array}{l}366 \\
(39.1)\end{array}$ & $304(46.3)$ & $62(22.1)$ & \\
\hline \multicolumn{5}{|c|}{ Source considered the most reliable regarding COVID-19 information } \\
\hline Healthcare workers & $\begin{array}{l}520 \\
(55.6)\end{array}$ & $377(57.5)$ & $143(51.1)$ & \\
\hline Healthcare officials & $98(10.5)$ & $72(11)$ & $26(9.3)$ & \\
\hline Social media & $\begin{array}{l}121 \\
(12.9)\end{array}$ & $71(10.8)$ & $50(17.9)$ & $<0.001$ \\
\hline Scientific literature/internet & $\begin{array}{l}146 \\
(15.6)\end{array}$ & $117(17.8)$ & $29(10.4)$ & \\
\hline Other sources & $51(5.4)$ & $19(2.9)$ & $32(11.4)$ & \\
\hline
\end{tabular}

TABLE 2: Responses on vaccine acceptance $(\mathrm{N}=936)$

COVID-19: coronavirus disease 2019

Overall, $70.1 \%$ of the population reported willingness to get the COVID-19 vaccine if available and recommended by healthcare workers. When asked if they would get the vaccine with $95 \%$ effectiveness for a cost, $77.1 \%$ of our respondents responded in the affirmative, compared to only $41.2 \%$ who were willing to get vaccinated with a $50 \%$ effective vaccine for a cost. In contrast, $85.4 \%$ stated they would get vaccinated with a $95 \%$ effective vaccine if freely available. Whereas $55.7 \%$ stated that they would get vaccinated with a $50 \%$ effective vaccine if freely available. Table 3 presents a univariate analysis of the findings.

\begin{tabular}{|c|c|c|c|}
\hline Variable & Odds ratio & $95 \%$ confidence intervals & p-value \\
\hline \multicolumn{4}{|l|}{ Age (years) } \\
\hline 18-19 & \multicolumn{2}{|l|}{ [reference] } & \\
\hline $20-29$ & 2.04 & $1.48-2.79$ & $<0.001$ \\
\hline 30-39 & 1.40 & $0.86-2.27$ & 0.17 \\
\hline $40-49$ & 1.86 & $0.72-4.78$ & 0.19 \\
\hline $50-59$ & 0.78 & $0.36-1.70$ & 0.54 \\
\hline$>60$ & 0.51 & $0.18-1.45$ & 0.21 \\
\hline \multicolumn{4}{|l|}{ Gender } \\
\hline Female & \multicolumn{2}{|l|}{ [reference] } & \\
\hline Male & 1.47 & $1.10-1.97$ & 0.009 \\
\hline \multicolumn{4}{|l|}{ Province } \\
\hline Gilgit-Baltistan & [reference] & & \\
\hline
\end{tabular}




\section{Cureus}

\begin{tabular}{|c|c|c|c|}
\hline Sindh & 1.63 & $0.47-5.55$ & 0.43 \\
\hline Punjab & 0.95 & $0.28-3.20$ & 0.93 \\
\hline Balochistan & 0.91 & $0.22-3.68$ & 0.90 \\
\hline Khyber Pakhtunkhwa & 1.38 & $0.36-5.18$ & 0.63 \\
\hline \multicolumn{4}{|l|}{ Education } \\
\hline No formal education & [reference] & & \\
\hline Primary school & 2.2 & $0.17-28.13$ & 0.54 \\
\hline Secondary school & 3.52 & $1.33-9.25$ & 0.01 \\
\hline Bachelor/university & 2.9 & $1.21-6.96$ & 0.01 \\
\hline Master/PhD & 1.89 & $0.76-4.68$ & 0.16 \\
\hline Diploma & 0.82 & $0.21-3.21$ & 0.78 \\
\hline \multicolumn{4}{|l|}{ Occupation } \\
\hline Unemployed/retired & [reference] & & \\
\hline Private sector & 1.30 & $0.8-2.11$ & 0.28 \\
\hline Government employee & 2.51 & $0.99-6.35$ & 0.052 \\
\hline Business & 0.7 & $0.33-1.48$ & 0.36 \\
\hline Student & 0.77 & $0.52-1.14$ & 0.20 \\
\hline \multicolumn{4}{|c|}{ Income (in Pakistani rupees) } \\
\hline$<10,000$ & [reference] & & \\
\hline $10,000-49,999$ & 1.09 & $0.5-2.34$ & 0.82 \\
\hline $50,000-100,000$ & 1.45 & $0.65-3.21$ & 0.35 \\
\hline$>100,000$ & 1.67 & $0.77-3.60$ & 0.18 \\
\hline \multicolumn{4}{|l|}{ Marital status } \\
\hline Married & [reference] & & \\
\hline Single & 1.09 & $0.77-1.52$ & 0.61 \\
\hline Divorced & 0.25 & $0.09-0.68$ & 0.007 \\
\hline \multicolumn{4}{|l|}{ Occupation } \\
\hline None of the below & [reference] & & \\
\hline Healthcare worker & 2.12 & $1.33-3.38$ & 0.002 \\
\hline Medical students & 1.36 & $0.99-1.86$ & 0.054 \\
\hline \multicolumn{4}{|c|}{ Presence of COVID-19 infection in family or friends } \\
\hline No & [reference] & & \\
\hline Yes & 2.04 & $1.52-2.73$ & \\
\hline \multicolumn{4}{|l|}{ Comorbidity } \\
\hline No & [reference] & & \\
\hline Yes & 1.08 & $0.72-1.63$ & 0.69 \\
\hline \multicolumn{4}{|c|}{ Perceived risk of being infected with COVID-19 } \\
\hline $0-30 \%$ & [reference] & & \\
\hline $40-60 \%$ & 1.68 & $1.22-2.29$ & 0.001 \\
\hline
\end{tabular}




\section{Cureus}

Confidence in the reliability of media sources regarding COVID-19

No

[reference]

Yes

$1.66-3.07$

$<0.001$

Influenza/flu vaccine/flu shots administered every year

No

[reference]

Yes

1.47

$1.05-2.07$

0.02

Trust in the national government to control the pandemic

No

[reference]

Yes

1.74

$1.30-2.33$

$<0.001$

COVID-19 can be debilitating and dangerous to health

No

[reference]

Yes

2.67

$2-3.58$

$<0.001$

Source considered the most reliable regarding COVID-19 information

Healthcare workers

[reference]

Healthcare officials

1.05

$0.64-1.71$

0.84

Social media

0.53

$0.35-0.81$

0.003

Scientific literature/internet

$0.97-2.4$

0.64

Other sources

0.22

$0.12-0.41$

$<0.001$

\section{TABLE 3: Univariate analysis of the determinants of COVID-19 vaccine acceptance}

COVID-19: coronavirus disease 2019

Over $27.3 \%$ of the respondents did not perceive the media to be a reliable source of information regarding COVID-19, whereas $38.9 \%$ perceived it to be reliable, and the remaining (33.8\%) were neutral to media outlets. When asked to choose what they perceived to be the most reliable source of information regarding COVID-19, 66\% of the respondents chose healthcare workers and officials, $15.6 \%$ chose scientific literature and the internet, and $12.9 \%$ chose social media.

The multivariate analysis identified that first male gender, second healthcare workers and medical students, third respondents whose family or friends had contracted COVID-19, and fourth individuals who trusted media as a reliable source for COVID-19 were more receptive to the vaccine. Participants' belief that COVID-19 can be debilitating and dangerous to their health was also significantly linked to greater acceptance of the vaccine. The results of the multivariate analysis are depicted in Table 4 . 


\section{Cureus}

\begin{tabular}{|c|c|c|}
\hline Variable & Odds ratio $(95 \%$ confidence intervals) & p-value \\
\hline \multicolumn{3}{|l|}{ Gender } \\
\hline Female & [reference] & \\
\hline Male & $1.65(1.2-2.26)$ & 0.002 \\
\hline \multicolumn{3}{|l|}{ Occupation } \\
\hline None of the below & [reference] & \\
\hline Healthcare worker & $2.1(1.25-3.51)$ & 0.005 \\
\hline Medical students & $1.64(1.16-2.31)$ & 0.004 \\
\hline \multicolumn{3}{|c|}{ Presence of COVID-19 infection in family or friends } \\
\hline No & [reference] & \\
\hline Yes & $2.11(1.53-2.91)$ & $<0.001$ \\
\hline \multicolumn{3}{|c|}{ Confidence in the reliability of media sources regarding COVID-19 } \\
\hline No & [reference] & \\
\hline Yes & $2.11(1.48-3.01)$ & $<0.001$ \\
\hline \multicolumn{3}{|c|}{ Trust in the national government to control the pandemic } \\
\hline No & [reference] & \\
\hline Yes & $1.49(1.06-2.10)$ & 0.02 \\
\hline \multicolumn{3}{|c|}{ COVID-19 can be debilitating and dangerous to health } \\
\hline No & [reference] & \\
\hline Yes & 2.28 (1.68-3.11) & $<0.001$ \\
\hline
\end{tabular}

\section{TABLE 4: Multivariate analysis of the determinants of COVID-19 vaccine acceptance}

\section{Discussion}

The COVID-19 vaccine is being rolled out using a phased approach to immunize individuals in Pakistan to achieve herd immunization. Our study shows that males, healthcare workers, and medical students are more likely to accept the vaccine, whereas the chances of immunizing the masses are higher if the vaccine is given free of cost. Irrespective of vaccination costs, a statistically higher proportion of individuals were keen on getting the vaccine with a $95 \%$ efficacy as opposed to those with $50 \%$ efficacy rates.

Previously conducted surveys found that adequate knowledge among the general public is a critical determinant of infection prevention and control. In contrast to the more severe second wave of COVID-19 infection in Pakistan, a large cross-sectional survey of 1200 Pakistani residents during the first wave found that $93.3 \%$ of the surveyed population had adequate knowledge of COVID-19 precautionary measures [8]. Our study indicates that $70.1 \%$ of the population were willing to get the vaccine if it became available and was recommended by a credible source. The finding is aligned with India, another LMIC that has similar literacy rates, and socio-economic conditions to Pakistan. The vaccine acceptance measured among the general public in India was found to be 74\% [9]. Among countries with higher incomes and literacy, scientific literature notes lower acceptance rates for the vaccine; with 64.7\% in Saudi Arabia [10] and 67\% in the United States [7].

We evaluated the importance of factors such as the cost of the vaccine, reported effectiveness, and the duration of protection in determining acceptability in the population. The data showed that if a paid vaccine with $95 \%$ and $50 \%$ effectiveness became available, only $77.1 \%$ and $41.2 \%$ of the participants would, respectively, get the vaccine. However, if the two vaccines were made available free of cost, the acceptance would increase to $85.4 \%$ and $55.7 \%$ concerning vaccines with $95 \%$ and $50 \%$ effectiveness, respectively. This was in line with the results published by Harapan and colleagues from Indonesia, where $93 \%$ and $67 \%$ of the participants were willing to receive the vaccine if provided free of cost with a $95 \%$ and $50 \%$ effectiveness, 
respectively [6]. Prominent works such as Jeffery and colleagues showed that the differences in acceptance rates ranged from $90 \%$ in China to less than $55 \%$ in Russia [11].

The myth about the COVID-19 infection and vaccination persists in Pakistan, with religious undertones in the country [12]. Sentiments have been expressed such as the virus being an attack on Islamic nations and the vaccine containing micro-chips allowing governments to gain control of vaccinated individuals through the introduction of fifth-generation technology [12]. Ultimately, this has led to lower community trust, as documented with a $44.5 \%$ trust in the government shown in our study. These are worrisome trends since several studies report that populations with higher trust in the national healthcare systems are associated with higher vaccine acceptance and other health services $[13,14]$. Our data also revealed that $66 \%$ of the population considered healthcare professionals and officials as a reliable source of information for COVID19. Furthermore, a large proportion of vaccine acceptance is seen among healthcare workers and student groups as compared to non-healthcare workers. A systematic analysis by Vasilevska and colleagues found that healthcare workers are at a greater risk of contracting the infection and the central means of protecting themselves, and their families are through vaccination [15]. Healthcare workers may be further engaged by utilizing social media as a means to promote the importance of COVID-19 vaccine acceptance among the community.

Amyn and colleagues evaluated the determinants of COVID-19 vaccine acceptance among the general population in the United States [7]. The general public showed a lower interest in being vaccinated as compared to our study participants; $67 \%$ in the United States versus $71 \%$ in our study [7]. The study showed that $72 \%$ males, $78 \%$ adults aged 55 years or above, $81 \%$ Asians, and $75 \%$ college and/or graduate degree holders were more willing to accept the vaccine as compared to other groups [7]. Even though we had a lower representation of the older age groups in Pakistan, of the 43 older aged individuals who completed the survey, 23 (53.4\%) of the individuals were willing to get the COVID-19 vaccine. Similarly, 608 (65\%) university students with a bachelor's degree and 199 (21.3\%) individuals with a higher-level degree were more willing to partake in the immunization program as opposed to the $21(2.2 \%)$ lesser-educated individuals.

Gul Deniz and colleagues conducted an online survey to ascertain the hesitancy of vaccine administration in the United Kingdom and Turkey [16]. In both countries, around 3\% of the individuals presented with no intention of obtaining the COVID-19 vaccine, where 31\% of participants in Turkey and 14\% in the United Kingdom were unsure about the vaccine [16]. Overall, 54\% of the participants in Turkey and $63 \%$ in the United Kingdom believed that the outbreak of the novel coronavirus was natural, with no attributable conspiracy theories, finally leading to increased willingness of obtaining the COVID-19 vaccine [16].

\section{Limitations}

The present study had certain limitations. Firstly, due to the state-wide lockdowns, the available method to distribute the survey was a multitude of online platforms, employing the non-probability convenient sampling strategy which may not portray an accurate image of the participants in our population. Secondly, groups with limited access to online platforms could not fill our survey, leading to an underrepresentation of individuals from lower socioeconomic classes. Thirdly, around $80 \%$ of the participants were aged 30 years or less, and had a bachelor's degree, leading to an overestimation of vaccine acceptance among the Pakistani population. Notably, the survey was distributed using social media platforms with 76 million Internet users in Pakistan; of which, 63\% of users were in the age group of 20 to 25 years, according to the Pakistan Telecommunication Authority [17]. Lastly, this study did not measure the knowledge of COVID-19 among the participants, therefore, we were unable to derive any associations of acceptance with previous knowledge of the disease. However, our study is the first to assess the large-scale acceptance of COVID-19 in Pakistan that strategically evaluates vaccine uptake behaviors tied in with demographic and geographic factors across the country. During the data collection of this survey, several reports were available reporting the efficiencies of vaccines, therefore our findings are based on real-time associations of vaccine trials and administration to acceptance by the Pakistani population.

\section{Conclusions}

This is the first study from Pakistan that depicts the population-level acceptance of the COVID-19 vaccine and the influencing factors. These contributors vary significantly with demographics and geographical disparities. Based on our study findings, the most important determinants of vaccine acceptance were, first, dissemination of credible information, second, source of evidence like healthcare workers or government officials, third, social media influencer channels, and fourth media outlets. The central determinants of vaccine acceptance in Pakistan may be optimized for public health vaccination the governmental and health sector level to increase compliance of vaccine administration across low- and middle-income countries. The social determinants of vaccine acceptance, demographical and geographical differences, may be utilized to recommend targeted public health strategies and uniform vaccine rollouts for the ongoing COVID-19 pandemic and global outbreaks in the future.

\section{Additional Information}




\section{Disclosures}

Human subjects: Consent was obtained or waived by all participants in this study. Ethical Review Committee of Islamic International Medical College, Rawalpindi issued approval Riphah/IIMC/ ERC/146. This letter is to inform you that ERC has reviewed your research project with the title of "Acceptance of COVID-19 vaccine in the Adult Pakistani Population." The contingencies have been addressed and the IRB approves the protocol. Work on this project may begin. This approval is for a period of one year from the date of this letter and will require continuation approval if the research project extends beyond the approved time period. If you make any changes to the protocol during the period of this approval, you must submit a revised protocol to the ERC for approval before implementing the changes. Animal subjects: All authors have confirmed that this study did not involve animal subjects or tissue. Conflicts of interest: In compliance with the ICMJE uniform disclosure form, all authors declare the following: Payment/services info: All authors have declared that no financial support was received from any organization for the submitted work. Financial relationships: All authors have declared that they have no financial relationships at present or within the previous three years with any organizations that might have an interest in the submitted work. Other relationships: All authors have declared that there are no other relationships or activities that could appear to have influenced the submitted work.

\section{Acknowledgements}

Mohammad Aadil Qamar and Omar Irfan contributed equally to this study as joint first authors. The authors would like to thank Shiza Siddiqui (Dow International Medical College), Qosain Fatima Suriya (Aga Khan University Hospital), and Hani Ali Khan (Rehman Medical College) for assisting in data collection.

\section{References}

1. WHO coronavirus (COVID-19) dashboard. (2021). Accessed: July 1, 2021: https://covid19.who.int/.

2. Tillett RL, Sevinsky JR, Hartley PD, et al.: Genomic evidence for reinfection with SARS-CoV-2: a case study . Lancet Infect Dis. 2021, 21:52-8. 10.1016/S1473-3099(20)30764-7

3. Ali M, Ahmad N, Khan H, Ali S, Akbar F, Hussain Z: Polio vaccination controversy in Pakistan. Lancet. 2019, 394:915-6. 10.1016/S0140-6736(19)32101-4

4. Vaccine rumours debunked: microchips, 'altered DNA' and more . (2020). Accessed: July 1, 2021: https://www.bbc.com/news/54893437.

5. Govt warns stern actions against traders who raise face mask price: Nausheen Hamid . (2020). Accessed: July 1, 2021: https://dailytimes.com.pk/567976/govt-warns-stern-actions-against-traders-who-raise-face-maskprice-nausheen-hamid/.

6. Harapan H, Wagner AL, Yufika A, et al.: Acceptance of a COVID-19 vaccine in Southeast Asia: a crosssectional study in Indonesia. Front Public Health. 2020, 8:381. 10.3389/fpubh.2020.00381

7. Malik AA, McFadden SM, Elharake J, Omer SB: Determinants of COVID-19 vaccine acceptance in the US . EClinicalMedicine. 2020, 26:100495. 10.1016/j.eclinm.2020.100495

8. Ladiwala ZF, Dhillon RA, Zahid I, Irfan O, Khan MS, Awan S, Khan JA: Knowledge, attitude and perception of Pakistanis towards COVID-19; a large cross-sectional survey. BMC Public Health. 2021, 21:21. 10.1186/s12889-020-10083-y

9. Sallam M: COVID-19 vaccine hesitancy worldwide: a concise systematic review of vaccine acceptance rates . Vaccines (Basel). 2021, 9:160. 10.3390/vaccines9020160

10. Al-Mohaithef M, Padhi BK: Determinants of COVID-19 vaccine acceptance in Saudi Arabia: a web-based national survey. J Multidiscip Healthc. 2020, 13:1657-63. 10.2147/JMDH.S276771

11. Lazarus JV, Ratzan SC, Palayew A, et al.: A global survey of potential acceptance of a COVID-19 vaccine . Nat Med. 2021, 27:225-8. 10.1038/s41591-020-1124-9

12. Khan YH, Mallhi TH, Alotaibi NH, Alzarea AI, Alanazi AS, Tanveer N, Hashmi FK: Threat of COVID-19 vaccine hesitancy in Pakistan: the need for measures to neutralize misleading narratives. Am J Trop Med Hyg. 2020, 103:603-4. 10.4269/ajtmh.20-0654

13. Quinn SC, Jamison AM, An J, Hancock GR, Freimuth VS: Measuring vaccine hesitancy, confidence, trust and flu vaccine uptake: results of a national survey of White and African American adults. Vaccine. 2019, 37:1168-73. 10.1016/j.vaccine.2019.01.033

14. Musa D, Schulz R, Harris R, Silverman M, Thomas SB: Trust in the health care system and the use of preventive health services by older black and white adults. Am J Public Health. 2009, 99:1293-9. 10.2105/AJPH.2007.123927

15. Vasilevska M, Ku J, Fisman DN: Factors associated with healthcare worker acceptance of vaccination: a systematic review and meta-analysis. Infect Control Hosp Epidemiol. 2014, 35:699-708. 10.1086/676427

16. Salali GD, Uysal MS: COVID-19 vaccine hesitancy is associated with beliefs on the origin of the novel coronavirus in the UK and Turkey. Psychol Med. 2020, 1-3. 10.1017/S0033291720004067

17. Estimating broadband end-users and their experience of service and its performance . (2010). Accessed: July 1, 2021: https://www.pta.gov.pk/media/bb_sub_sur_report_10.pdf. 